\title{
Recombinant Mouse $\beta$-Defensin 3 Protects against Coxsackievirus B3-Induced Myocarditis in Mice
}

\author{
Yan Jianga, bongjin Zhu ${ }^{a}$ Li Luo ${ }^{a}$ Qiuju Mu ${ }^{a}$ Yanxin Zhu ${ }^{a}$ Hong Luo ${ }^{b}$ \\ Xijun Zou ${ }^{b}$ Xiangchun Shen ${ }^{c}$ \\ ${ }^{a}$ Department of Microbiology, ${ }^{\mathrm{b}}$ Laboratory Animal Center, and ${ }^{\mathrm{C}}$ Key Laboratory of Optimal Utilization of \\ Natural Medicinal Resources, Guizhou Medical University, Guiyang, PR China
}

\section{Key Words}

$\beta$-Defensin $3 \cdot$ Coxsackievirus B3 · Antiviral activity · Viral myocarditis

\begin{abstract}
Objectives: To investigate the protective effect of recombinant mouse $\beta$-defensin 3 ( $r M B D 3$ ) against coxsackievirus B3 (CVB3)-induced myocarditis in mice. Methods: CVB3-infected HeLa cells were treated with rMBD3, and the titer of CVB3 and the proliferative activities of the cells were determined. CBV3-infected BALB/C mice were divided into five groups: rMBD3 high (5 mg/kg/day, q.d.), rMBD3 low (2.5 mg/kg/day, q.d.), ribavirin (10 mg/kg/day, q.d.), normal control, and myocarditis control. On days 5 and 12 after treatment, 3 mice from each group were sacrificed and serum lactate dehydrogenase, creatine kinase-MB isozyme, and tumor necrosis factor-a levels were determined. The heart index and the inflammation of myocardial tissue were also assessed. On day 5, the CVB3 50\% tissue culture infective dose $\left(\mathrm{TCID}_{50}\right)$ values of heart tissues were measured. Results: rMBD3 inhibited the replication of CVB3 and protected HeLa cells from infection. rMBD3 reduced the CVB3 titer markedly and inhibited the pathological reaction of cardiac myocytes to viral myo-
\end{abstract}

carditis. Treatment with rMBD3 improved the cell survival rate and reduced the cardiac index. Conclusion: rMBD3 was demonstrated to possess anti-CVB3 activity in vivo and in vitro.

(c) 2016 S. Karger AG, Basel

\section{Introduction}

Antimicrobial peptides are important components of the innate immune system, and more than 4,000 antimicrobial peptides have been identified. Defensins are essential mammalian antimicrobial peptides. $\beta$-Defensins, which have been identified in many cell types, including epithelial cells and neutrophils, play an important role in inflammation, wound healing, and regulation of specific immunity reactions [1]. Antimicrobial peptides and their elicitors have become a new hope for the postantibiotic era [2]. In terms of antiviral activities, defensins have reported effects on coated viruses, such as influenza virus [3], human immunodeficiency virus (HIV) [4], and herpes simplex virus [5]. In addition, Gounder et al. [6] reported that human a-defensin 5 (HD5) has activity against nonenveloped viruses. It was confirmed that HD5 
blocks infection by nonenveloped viruses, including human adenoviruses, papillomaviruses, and polyomaviruses. The detailed mechanisms by which defensins protect against both enveloped and nonenveloped viruses were reviewed recently by Wilson et al. [10].

Coxsackievirus B (CVB), in particular coxsackievirus B3 (CVB3), belongs to an enterovirus genus in the Picornaviridae family and is the most frequent etiological agent to induce myocarditis, particularly in newborns and children $[8,9]$. At present, no vaccines or antiviral agents are available; therefore, there is an urgent need for an antiviral agent or cure [10].

The therapeutic methods for viral myocarditis are mainly supportive, such as bed rest, vitamin C, and coenzyme Q10 [8]. Some studies have supported a role for both immunoregulatory and antiviral therapies in the treatment of myocarditis. Until now, few effective drugs have been available to treat the disease, and severe cases have a poor prognosis without heart transplantation [11, $12]$. To treat viral myocarditis, ribavirin (RB) has been found to exhibit potent antiviral properties vital for the clinical treatment of viral diseases [13]; however, its use remains controversial because of its questionable efficacy, side effects, and high cost.

In our previous study, recombinant mouse $\beta$-defensin 3 (rMBD3) was obtained using a prokaryotic expression system, and its antibacterial, antifungal, and anti-influenza viral activities were verified $[14,15]$. In the present study, rMBD3 was investigated for its anti-CVB3 activity and treatment of viral myocarditis in vitro and in vivo.

\section{Materials and Methods}

\section{rMBD3 Peptides and Reagents}

A prokaryotic expression system comprising engineered bacteria Rosetta-gami(2)-pET32a(+)/MBD3 was constructed [15]. rMBD3 was obtained by inducing expression, followed by Ni-affinity chromatography, thrombosin digestion, and a further $\mathrm{Ni}$ affinity chromatography step, which were all performed according to standard procedures. Mass spectrometry, sodium dodecyl sulfate polyacrylamide gel electrophoresis, and Western blotting were used to verify the molecular weight and specificity of rMBD3 [15]. Purified rMBD3 was diluted in $10 \mathrm{~mm}$ phosphate buffer $(8.2 \mathrm{~mm}$ $\mathrm{Na}_{2} \mathrm{HPO}_{4}, 1.8 \mathrm{mM} \mathrm{KH}_{2} \mathrm{PO}_{4}, \mathrm{pH} 7.4$ ) and tested for cytotoxicity and antiviral activities at $62.5-2,000 \mu \mathrm{g} / \mathrm{ml}$ [14]. RB (Guizhou Guangzheng Pharmaceutical Company, China) was diluted in sterile distilled water.

Virus, Cells, and Media

CVB3 (Nancy strain) was purchased from the Wuhan Institute of Virology, Chinese Academy of Sciences. The virus was prepared in HeLa cells (Kunming Committee Type Culture Collection Cell Bank, Chinese Academy of Sciences), cultured in RPMI-1640 (Hy-
Clone, Logan, Utah, USA), and the 50\% tissue culture infective dose $\left(\mathrm{TCID}_{50}\right)$ was determined. HeLa cells were grown in RPMI1640 supplemented with $10 \%$ fetal bovine serum (FBS; Hyclone).

\section{3-[4,5-Dimethylthiazol-2-yl]-2,5 Diphenyl Tetrazolium}

Bromide Assay

The cytotoxicity and antiviral activity of rMBD3 were evaluated by 3-[4,5-dimethylthiazol-2-yl]-2,5 diphenyl tetrazolium bromide assay (MTT; Solarbio, Beijing, China) as previously described [15]. Briefly, $10^{5}$ cells/well were seeded into 96-well culture plates (Costar, Cambridge, Mass., USA). After 2-3 days of incubation at $37^{\circ} \mathrm{C}$ with $5 \% \mathrm{CO}_{2}$, the cytotoxicity and antiviral tests were performed. The media were aspirated, cells were rinsed with phosphate-buffered saline (PBS), and then the MTT reagent $(5 \mathrm{mg} / \mathrm{ml})$ was added. The plate was reincubated for an additional $4 \mathrm{~h}$, and then $100 \mu \mathrm{l}$ of dimethyl sulfoxide (Solarbio) was added to each well. Optical densities were determined using a plate reader (ELx800 light absorption enzyme standard instrument; BioTek, USA) at a wavelength of $492 \mathrm{~nm}$.

\section{TCID $_{50}$ Assays}

CVB3 in tissue culture supernatant fluids was detected and titrated using the end-point method by infecting replicate HeLa cells in 96-well plastic dishes with serial 10-fold dilutions of suspected virus-containing supernatant fluids. The presence of the typical cytopathic effects of CVB3 was monitored in all replicate cells for 4 days (96 h). Based on these data, TCID $_{50}$ was calculated as previously described [17]. The rates were expressed as TCID $_{50}$ units $/ 0.1 \mathrm{ml}$.

\section{Cytotoxicity Assays of CVB3 to HeLa Cells or Mice}

HeLa cells were grown in RPMI-1640 medium, seeded into 96well tissue culture plates and different concentrations of rMBD3 were added to the medium (final concentrations were 200,100, 50 , or $25 \mu \mathrm{g} / \mathrm{ml}$ ). The cells were incubated at $37^{\circ} \mathrm{C}$ with $5 \% \mathrm{CO}_{2}$ for $72 \mathrm{~h}$. Cell proliferation and viability were determined using the MTT test. Specific pathogen-free female BALB/c mice (6 weeks old) were obtained from the Laboratory Animal Center of Guiyang Medical University (Guiyang, China). Ten mice were divided into two groups of 5 mice: (1) normal control (NC) group and (2) $\mathrm{rMBD} 3,10 \mathrm{mg} / \mathrm{kg} /$ day, once daily, by intraperitoneal injection. After 3 months, all mice were sacrificed and their heart, brain, lung, liver, and kidney pathologies were determined.

\section{Anti-CVB3 Assays}

The antiviral activity of rMBD3 was evaluated as described by Song et al. [18]. HeLa cells were grown to a monolayer in 96-well culture plates. The medium was aspirated and the cells were infected with $100 \times$ TCID $_{50}$ CVB3; then a series of concentrations of rMBD3 were added and the plates were placed at $4^{\circ} \mathrm{C}$ for $1 \mathrm{~h}$. After aspiration to remove unabsorbed viruses, cell monolayers were then washed with PBS three times and overlaid with $1 \%$ methylcellulose medium. The cell monolayer was incubated at $37^{\circ} \mathrm{C}$ for another $48 \mathrm{~h}$ before it was fixed and stained.

\section{Antiviral Effects of rMBD3 in Experimental Animals}

Specific pathogen-free female BALB/c mice (6 weeks old) were obtained from the Laboratory Animal Center of Guiyang Medical University (Guizhou, China). Mice were inoculated intraperitoneally with $0.1 \mathrm{ml} \mathrm{CVB3}$ suspension containing $1,000 \times \mathrm{TCID}_{50}$ on days $1,6,11$, and 16 (four times in total). The viral myocarditis 
mice were divided into groups of 15: (1) NC; (2) viral myocarditis (VM); (3) RB, $10 \mathrm{mg} / \mathrm{kg} /$ day, once daily, intraperitoneal injection; (4) low-dose rMBD3 (rMBD3-L), $2.5 \mathrm{mg} / \mathrm{kg} /$ day, once daily, intraperitoneal injection, and (5) high-dose rMBD3 (rMBD3-H), $5 \mathrm{mg} /$ $\mathrm{kg} /$ day, once daily, intraperitoneal injection. Treatment began $24 \mathrm{~h}$ after the first injection of CVB3 and was performed once a day for 4 weeks. Five and 12 days after the last injection of CVB3, 3 mice per group were sacrificed and the following was determined: serum lactate dehydrogenase ( $\mathrm{LDH})$, creatine kinase-MB isozyme (CK-MB), tumor necrosis factor- $\alpha$ (TNF- $\alpha$ ), IL-2, and IFN- $\gamma$ levels; the CVB3 $\mathrm{TCID}_{50}$ of heart tissues; heart pathology and heart index; the expressions of the CVB3 NTR gene, and the IFN- $\alpha,-\beta$, $-\gamma$, and TNF- $\alpha$ genes of heart tissues. The remaining 9 mice per group continued to be fed and their weights or mortality were measured until the end of the experiment.

\section{Enzymatic Assay for LDH Activity}

Serum LDH activity was measured within $2 \mathrm{~h}$ of collection using an LDH test kit (Nanjing Jiancheng Bioengineering Institute, China). The LDH activity was measured at $37^{\circ} \mathrm{C}$ using pyruvate as a substrate. The reduced nicotinamide adenine dinucleotide $(\mathrm{NADH})$ generated was determined by its absorbance at $450 \mathrm{~nm}$.

\section{ELISA Assay for CK-MB and TNF- $\alpha$ Content}

The serum samples collected at different points were assayed using ELISA kits (Wuhan Huamei Bioengineering Ltd., China) to measure CK-MB and TNF- $\alpha$, according to the manufacturer's instructions.

\section{Heart Index Analysis and Histological Examination}

To assay infectivity, mice were randomly chosen from each group on days 5 and 12. The heart weight/body weight ratio was determined and histological examination was performed. The degree of myocarditis was determined following a previously described scoring system [18], which ranged from 0 to 4 (1 corresponds to infiltration of up to $5 \%$ of the histological cross section; $2,5-10 \% ; 3,10-20 \%$, and 4 , more than $20 \%$. The observer was a pathologist who did not participate in the animal experiment.

\section{Statistical Analysis}

Data are presented in the text and figures as means \pm SD. Group-group comparison data were analyzed using a one-way ANOVA test, and a value of $\mathrm{p}<0.05$ was considered statistically significant.

\section{Results}

\section{Toxicity of $r M B D 3$}

Doses of $12.5-100 \mu \mathrm{g} / \mathrm{ml} \mathrm{rMBD} 3$ were not cytotoxic to HeLa cells, and cell proliferation was comparable to that of the control groups without rMBD3 (fig. 1). Therefore, these doses were used for subsequent antiviral studies. The mice in the rMBD3 group appeared normal and did not show increased mortality. In addition, the pathologies of the important organs were not different compared with those of the normal group.

Anti-CVB3 Activity of rMBD3

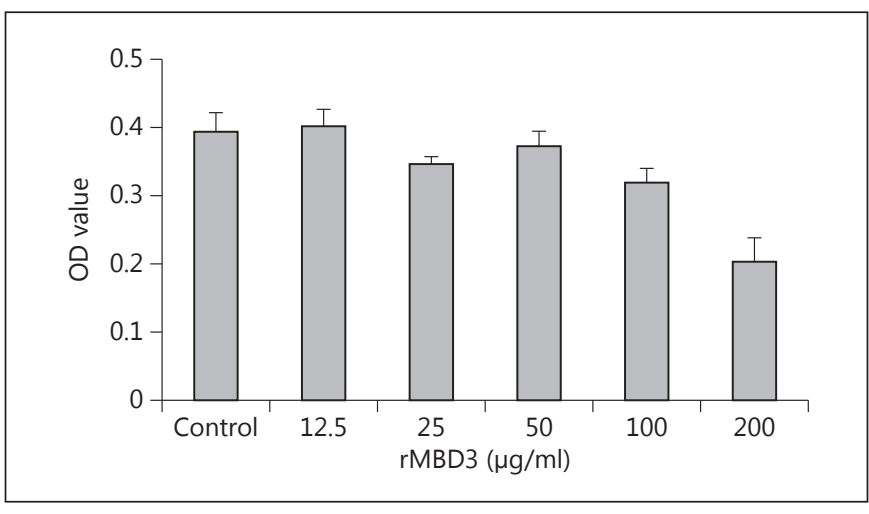

Fig. 1. Cytotoxicity of rMBD3 to HeLa cells. $200 \mu \mathrm{g} / \mathrm{ml}$ of rMBD3 was toxic to HeLa cells; however, $12.5-100 \mu \mathrm{g} / \mathrm{ml} \mathrm{rMBD} 3$ was not. Data are presented as the mean \pm SD of six wells of cells.

\section{rMBD3 Reduces CVB3 Replication}

This study examined the ability of rMBD3 to protect HeLa cells from infection by CVB3. rMBD3 appeared to protect HeLa cells from CVB3 infection (fig. 2a). rMBD3 effectively decreased the CVB3 titer in a dose-dependent manner, and $100 \mu \mathrm{g} / \mathrm{ml}$ rMBD3 could protect approximately $82 \%$ cells against CVB3 infection (fig. 2 b).

\section{rMBD3 Improved the Survival Rate of Mice Infected with CVB3}

On day 28, the high-dose rMBD3 group had a 5-fold higher survival rate than the CVB3-infected control group ( 62.5 vs. $12.5 \%$; $\mathrm{p}<0.05)$. The survival rate in the low-dose rMBD3 group was $50 \%$, showing that rMBD3 might have cardiac protective effects on mice with CVB3induced myocarditis. However, the RB group had a 22.2\% survival rate, much lower than that of the rMBD3-treated groups (fig. 3).

\section{rMBD3 Inhibited CVB3 and Protected the Heart from CVB3 Injury}

Three mice per group were killed on day 5 , and the $\mathrm{TCID}_{50}$ values of CVB3 of heart tissues in all treatment groups were significantly reduced (fig. 4). On days 5, 12, and 28 after infection, the severity of myocarditis was assessed using the heart index (table 1), morphometric analysis, and pathological grades (fig. 5; table 1). All treatment groups had lower heart indices compared with the viral myocarditis group. The heart index of the high-dose rMBD3 group was reduced by about $20 \%$ on day 5 (p $<$ $0.05)$. Histopathological evaluation was also carried out to confirm the presence and severity of myocarditis in the hearts of the viral myocarditis group. Infected hearts re- 


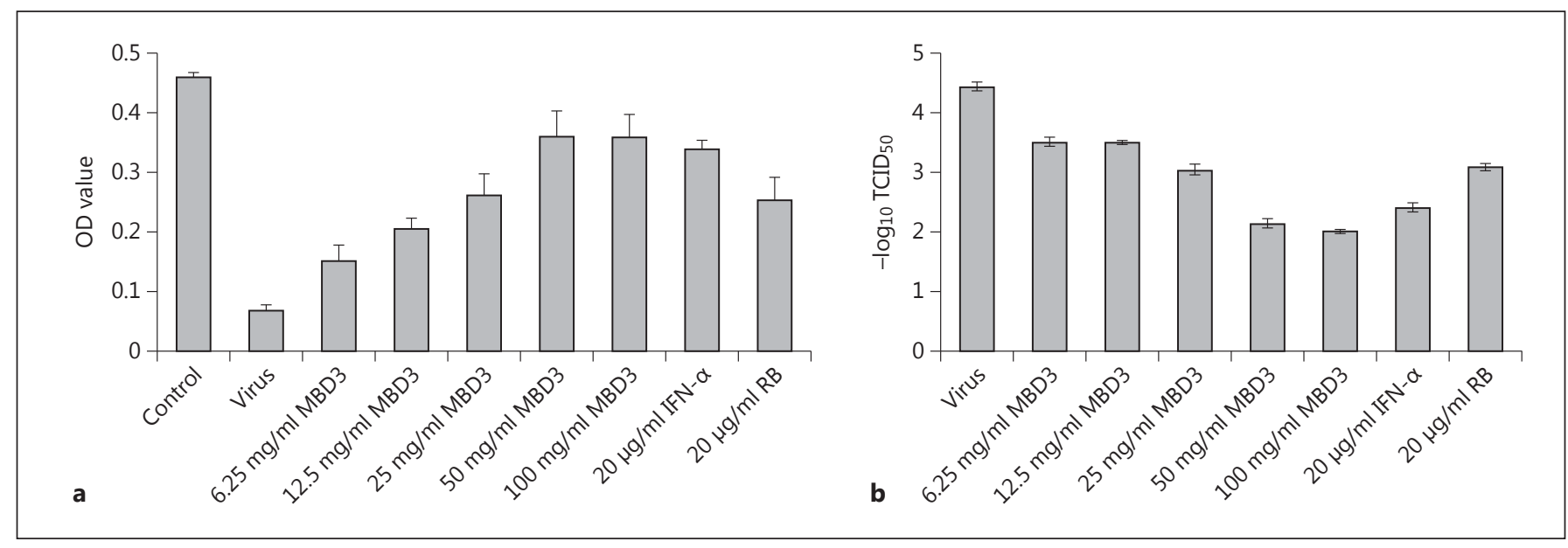

Fig. 2. rMBD3 inhibited CVB3 infection of HeLa cells. HeLa cells were infected with $100 \times \mathrm{TCID}_{50} \mathrm{CVB} 3$; rMBD3, IFN, or RB was added at $37^{\circ} \mathrm{C}$ for $2 \mathrm{~h}$. The proliferation of HeLa cells was determined using the MTT test. Data are presented as the mean $\pm \mathrm{SD}$ of six wells of cells.

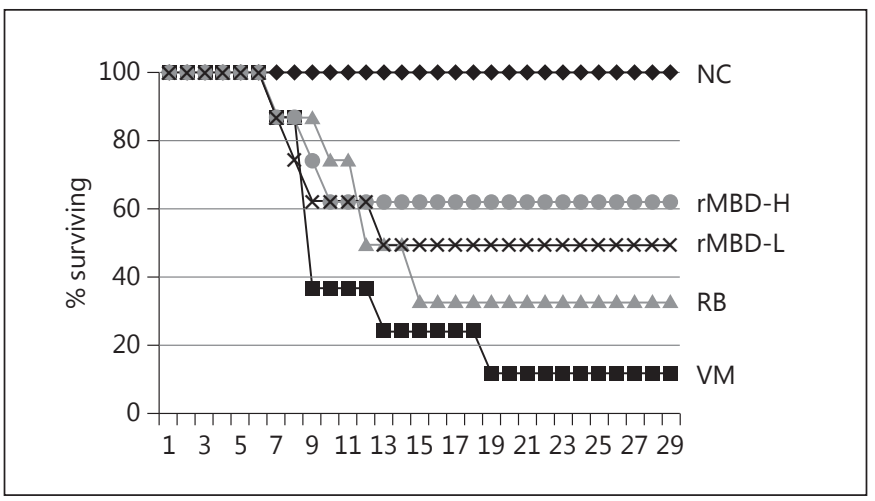

Fig. 3. rMBD3 prevented the death of mice from CVB3-induced myocarditis. The high-dose rMBD3 group showed 5-fold higher survival rates compared with the model group ( 62.5 vs. $12.5 \%, \mathrm{p}<$ $0.05 ; \mathrm{n}=5)$.

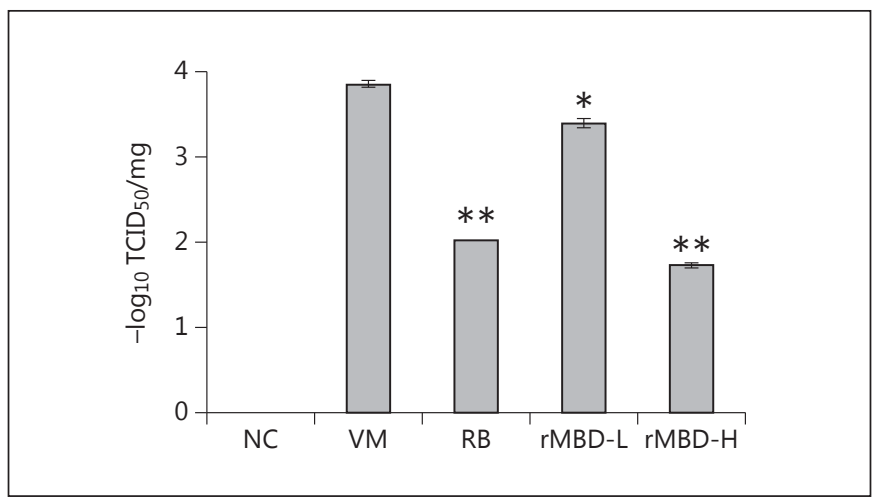

Fig. 4. $\mathrm{rMBD} 3$ reduced the CVB3 titer of mice heart tissues with CVB3-induced myocarditis. The $\mathrm{TCID}_{50}$ values of CVB3 of the heart tissues in all treatment groups were reduced. The reduction in the rMBD3-H group was significant. Data are shown as the mean $\pm \mathrm{SD}$ of 3 repetitions vs. the VM group. ${ }^{*} \mathrm{p}<0.05,{ }^{* *} \mathrm{p}<0.01$.

Table 1. The heart indices of the experimental mice

\begin{tabular}{llllll}
\hline Groups & $\begin{array}{l}5 \text { days } \\
\text { heart index }\end{array}$ & $\begin{array}{l}5 \text { days } \\
\text { pathological grades }\end{array}$ & $\begin{array}{l}\text { 12 days } \\
\text { heart index }\end{array}$ & $\begin{array}{l}\text { 12 days } \\
\text { pathological grades }\end{array}$ \\
\hline hC & $4.893 \pm 0.10$ & 0 & $4.949 \pm 0.13$ & 0 & $4.850 \pm 0.31$ \\
VM & $6.629 \pm 0.087$ & $3.82 \pm 0.11^{\#}$ & $5.635 \pm 0.25^{\#}$ & $3.67 \pm 0.18^{\#}$ & $5.184 \pm 0.44^{*}$ \\
rMBD3-L & $6.563 \pm 0.05^{*}$ & $3.42 \pm 0.51$ & $5.335 \pm 0.25^{*, \#}$ & $3.06 \pm 0.64^{*}$ & $4.771 \pm 0.20^{*, \#}$ \\
rMBD3-H & $5.273 \pm 0.21^{*, \#}$ & $2.66 \pm 0.39^{* *}$ & $4.932 \pm 0.35^{*}$ & $2.31 \pm 0.55^{* *}$ & $4.798 \pm 0.25^{\#}$ \\
RB & $6.004 \pm 0.15^{*}$ & $3.34 \pm 0.69$ & $5.103 \pm 0.17^{*, \#}$ & $3.1 \pm 0.57^{*}$ & $4.878 \pm 0.30$ \\
\hline
\end{tabular}

Results are expressed as means $\pm \mathrm{SD} .{ }^{*} \mathrm{p}<0.05$ vs. control group, ${ }^{* *} \mathrm{p}<0.01$ vs. control group, ${ }^{*} \mathrm{p}<0.05$ vs. the model group. 

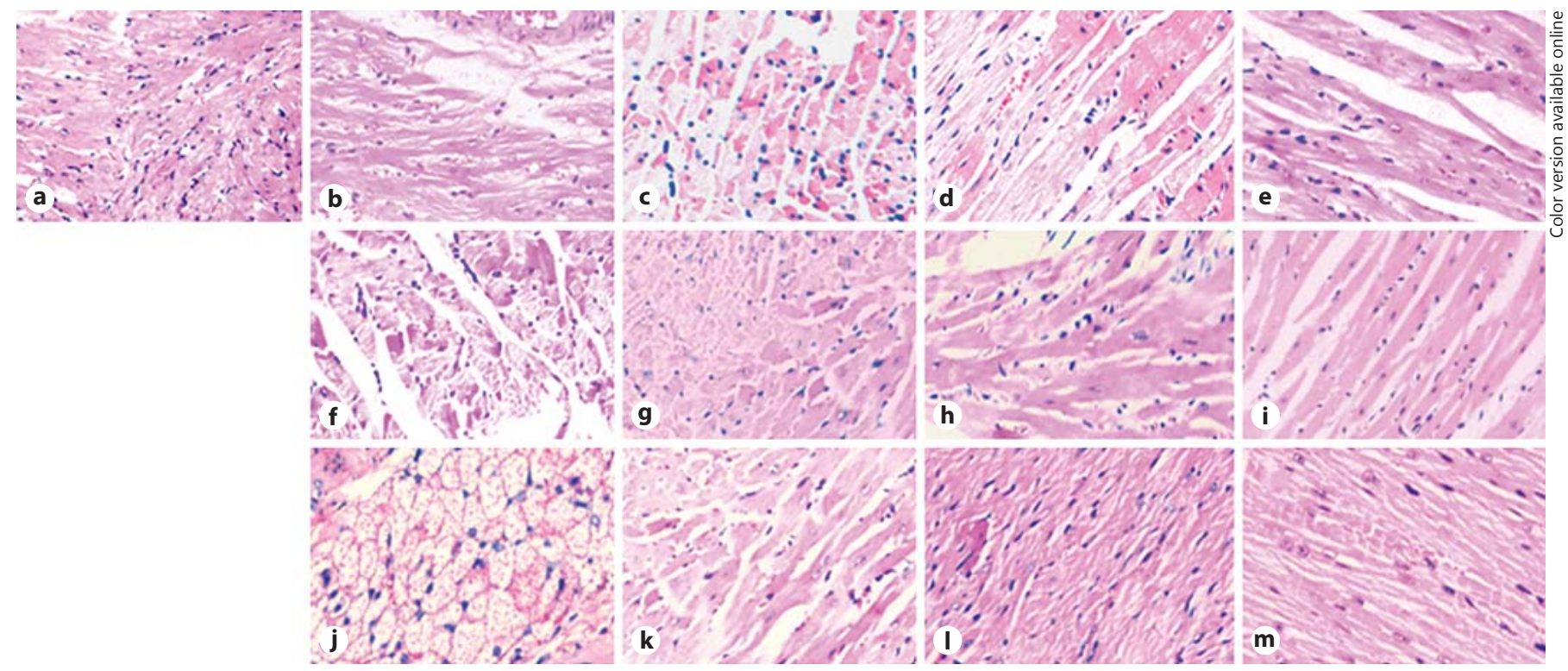

Fig. 5. rMBD3 showed protective effects on the pathological changes induced by CVB3 infection. Representative images of hematoxylin-eosin-stained cells (original magnification $\times 200$ ). a NC group. b VM group on day 5. c RB group on day 5. d rMBD3-L group on day 5. e rMBD3-H group on day 5. f VM group on day 12. $\mathbf{g}$ RB group on day 12. h rMBD3-L group on day 12. i rMBD3$\mathrm{H}$ group on day 12. j VM group on day 28. $\mathbf{k}$ RB group on day 28. I rMBD3-L group on day 28. $\mathbf{m}$ rMBD3-H group on day 28. vealed typical lesions of mononuclear cellular infiltration and necrosis. In contrast, no inflammatory reaction was found in noninfected mice via HE staining. According to the pathological grading, on day 5 , the tissue damage of the high-dose rMBD3 group was significantly reduced compared with the viral myocarditis group $(\mathrm{p}<0.01)$. Similar results were obtained on day 12 .

\section{The Levels of LDH, CM-CK, and TNF- $\alpha$ in Serum}

We investigated the levels of $\mathrm{LDH}, \mathrm{CM}-\mathrm{CK}$, and TNF- $\alpha$ in the serum of the mice on days 5,12 , and 28 . The levels of LDH, CM-CK, and TNF- $\alpha$ in the serum of the VM group were higher than in the NC group on days 5 , 12 , and 28 ; the greatest change was observed on day 5 . The levels of these proteins in the rMBD3-H, rMBD3-L, and $\mathrm{RB}$ groups were reduced by differing degrees versus that of the VM group ( $\mathrm{p}<0.05$ or $\mathrm{p}<0.01$; fig. 6 ).

\section{Discussion}

Our previous studies showed that rMBD3 has antiinfluenza A virus activity [14]. In the present study, we demonstrated that rMBD3 could effectively reduce viral replication in vitro and vivo, and reduced the inflammatory reaction and protected mice against viral myocardi- tis. These antiviral effects of eMBD3 were demonstrated in vitro and in vivo. In the cell experiments, rMBD3 directly reduced the replication of CVB3, and in the animal experiments, rMBD3 could prolong the survival of myocarditis mice and reduced the pathological changes and virus content in the cardiac muscle tissue.

The antiviral activities of defensins were traditionally thought to be directed only against enveloped viruses, such as influenza virus, HIV, and HSV. Subsequent research found that the defensins could inhibit a nonenveloped virus, such as adenovirus, human papilloma virus, and $\mathrm{BK}$ virus. The activity of defensins against nonenveloped viruses occurs through a variety of mechanisms. a-Defensin prevents virus particles being released from vesicles [20]. By blocking the entry of the virus into lung and conjunctival epithelial cells, human neutrophil defensin 1 and HD5 could inhibit adenovirus infections [21]. Human neutrophil defensin 1 and HD5 may prevent the receptor of BK virus combining with host cells. In our study, we found that rMBD3 directly reduced the titer of CVB3. In the cell experiments, rMBD3 was effective at decreasing the CVB3 titer in a dose-dependent manner, and $100 \mu \mathrm{g} / \mathrm{ml} \mathrm{rMBD} 3$ could reduce the titer of CVB3 by about $98 \%$ and protect approximately $82 \%$ of the cells against CVB3 infection. However, the antiviral mechanism of rMBD3 requires further research. 


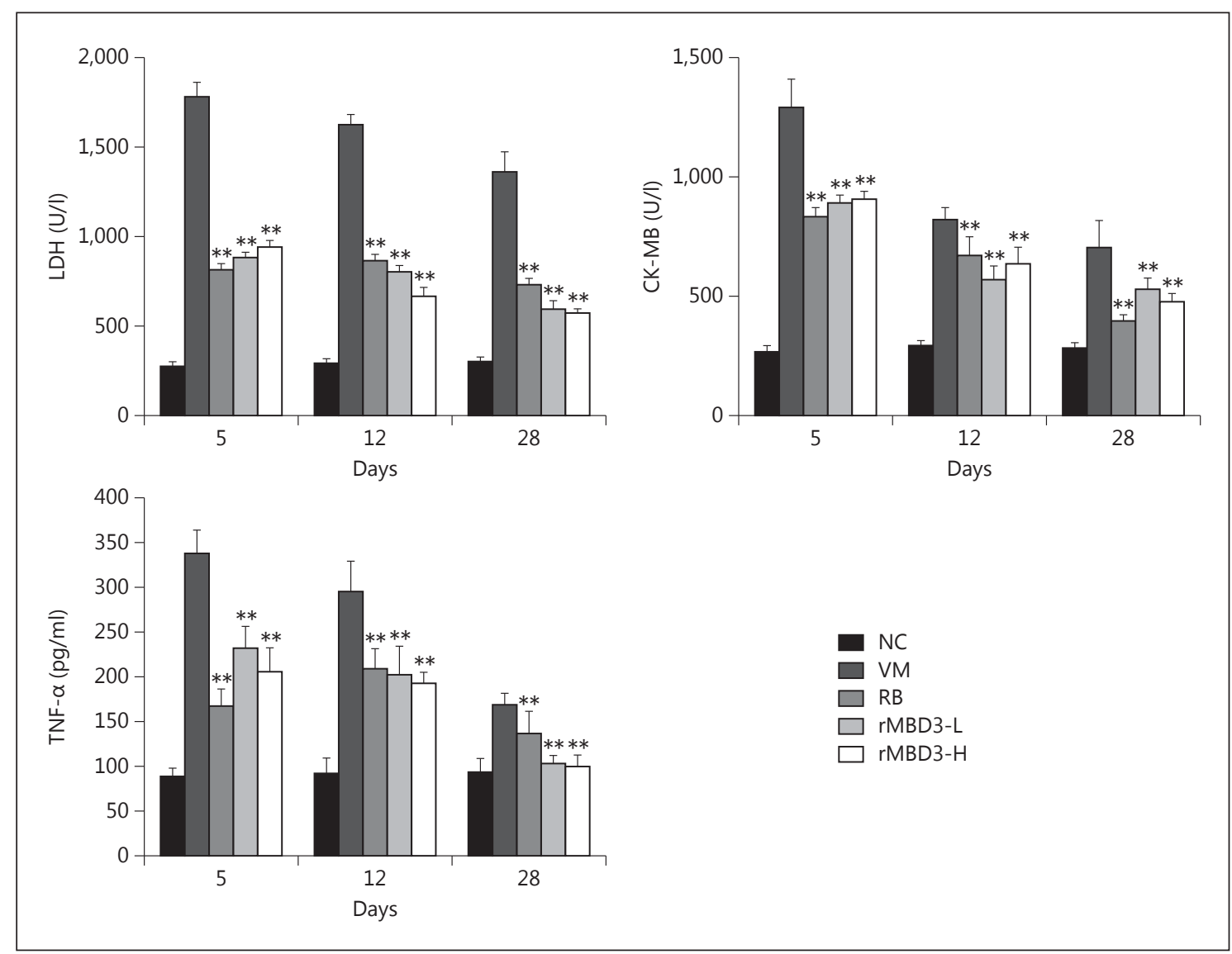

Fig. 6. The levels of LDH, CK-MB and TNF- $\alpha$ in the serum of mice on days 5, 12, and 28 after treatment. Data are presented as the mean \pm SD of 3 repetitions. ${ }^{* *} \mathrm{p}<0.01$.

In this study, coxsackievirus B3-induced myocarditis mice were used. rMBD3 reduced the titer of CVB3 in myocardial tissue of myocarditis mice. This explained the reduced pathological reaction of the cardiac myocytes and the cardiac index, as well as the improved survival rate induced by rMBD3 in myocarditis mice. However, we believe that rMBD3 is not the only factor involved in this process, and other factors need more in-depth study.

$\mathrm{LDH}$ and CK-MB are sensitive indicators that reflect myocardial damage, and are used to determine the outcome of myocarditis clinically. In our study, rMBD3 could induce increased levels of $\mathrm{LDH}$ and CK-MB in the myocardial tissue. TNF is a proinflammatory cytokine that has been implicated in the pathogenesis of cardiovascular diseases, including viral myocarditis. Control of TNF's destructive role in cardiovascular disease represents a realistic goal for clinical medicine [22]. In this study, rMBD3 was able to reduce the expression of TNF- $\alpha$ in cardiac muscle tissue. In serum, the content of TNF- $\alpha$ was reduced compared with the model group. The results showed that $\beta$-defensins affect the immune function, as reported previously $[23,24]$.

In summary, our study showed that rMBD3 has activity against CVB3 as part of its antimicrobial spectrum. As a small peptide with antibacterial, antifungal, antienveloped viral, and antinonenveloped viral activities, rMBD3 may be considered a good candidate agent to treat infectious diseases.

\section{Acknowledgements}

This work was supported by grants from the National Natural Science Foundation of China (No. 81260249), the Postdoctoral Fund of China (No. 2013M542302), the Science and Technology Department of Guizhou Province of China (No. [2013] 31 ), and Guizhou province science and technology research projects (SY [3085]). 


\section{References}

1 Sima P, Trebichavsky I, Sigler K: Mammalian antibiotic peptides. Folia Microbiol (Praha) 2003;48:123-137.

2 Prado Montes de Oca E: Antimicrobial peptide elicitors: new hope for the post-antibiotic era. Innate Immun 2013;19:227-241.

3 Leikina E, Ayari HD, Melikov K, Cho MS, Chen A, Waring AJ, Wang W, Xie Y, Loo JA, Lehrer RI, Chernomordik LV: Carbohydrate binding molecules inhibit viral fusion and entry by crosslinking membrane glycoproteins. Nat Immunol 2005;6:995-1001.

4 Demirkhanyan LH, Marin M, Padilla-Parra S, Zhan C, Miyauchi K, Jean-Baptiste M, Novitskiy G, Lu W, Melikyan GB: Multifaceted mechanisms of HIV-1 entry inhibition by human a-defensin. J Biol Chem 2012;287: 28821-28838.

5 Hazrati E, Galen B, Lu W, Wang W, Ouyang Y, Keller MJ, Lehrer RI, Herold BC: Human $\alpha$ - and $\beta$-defensins block multiple steps in herpes simplex virus infection. J Immunol 2006; 177:8658-8666.

6 Gounder AP, Wiens ME, Wilson SS, Lu W, Smith JG: Critical determinants of human a-defensin 5 activity against non-enveloped viruses. J Biol Chem 2012;287:24554-24562.

7 Wilson SS, Wiens ME, Smith JG: Antiviral mechanisms of human defensins. J Mol Biol 2013;425:4965-4980.

8 Elamm C, Fairweather D, Cooper LT: Pathogenesis and diagnosis of myocarditis. Heart 2012;98:835-840.
9 Pallansch M: Enteroviruses: Poliovirus, Coxsackieviruses, Echoviruses, and Newer Enteroviruses. Philadelphia, Lippincott Williams and Wilkins, 2007.

10 Magnani JW, Dec GW: Myocarditis: current trends in diagnosis and treatment. Circulation 2006;113:876-890.

11 Bean B: Antiviral therapy: current concepts and practices. Clin Microbiol 1992;5:146182.

12 Canter CE, Simpson KP: Diagnosis and treatment of myocarditis in children in the current era. Circulation 2014;129:115-128.

13 Sharma A, Marceau C, Hamaguchi R, Burridge $\mathrm{PW}$, Rajarajan $\mathrm{K}$, Churko JM, Wu $\mathrm{H}$, Sallam KI, Matsa E, Sturzu AC, Che Y, Ebert A, Diecke S, Liang P, Red-Horse K, Carette JE, Wu SM, Wu JC: Human induced pluripotent stem cell - derived cardiomyocytes as an in vitro model for coxsackievirus B3 - induced myocarditis and antiviral drug screening platform. Circ Res 2014;115:556-566.

14 Jiang Y, Wang YL, Kuang Y, Wang B, Li W, Gong TX, Jiang Z, Yang D, Li M: Expression of mouse beta-defensin 3 in MDCK cells and its anti-influenza-virus activity. Arch Virol 2009;154:639-647.

15 Jiang Y, Wang Y, Wang B, Yang D, Yu K, Yang X, Liu F, Jiang Z, Li M: Antifungal activity of recombinant mouse beta-defensin. Lett Appl Microbiol 2010;50:468-473.

16 Nishimura K, Tamaoki J, Isono K, Aoshiba K, Nagai A: $\beta$-Adrenergic receptor-mediated growth of human airway epithelial cell lines. Eur Respir J 2002;20:353-358.
17 Condit RC: Principles of Virology; in Knipe DM, Howley PM (eds): Fields virology, ed 5. Philadelphia, Lippincott, Williams and Wilkins, 2006, pp 25-57.

18 Song X, Liu Z, Wang H, Xin Y, Wang X, Chen J, Shi Y, Zhang C, Hui R: QiHong prevents death in coxsackievirus B3 induced murine myocarditis through inhibition of virus attachment and penetration. Exp Biol Med (Maywood) 2007;232:1441-1448.

19 Neu N, Rose NR, Beisel KW, Herskowitz A, Gurri-Glass G, Craig SW: Cardiac myosin induces myocarditis in genetically predisposed mice. J Immunol 1987;139:3630-3636.

20 Buck CB, Day PM, Thompson CD, Lubkowski J, Lu W, Lowy DR, Schiller JT: Human alpha-defensins block papillomavirus infection. Proc Natl Acad Sci USA 2006; 103:15161521.

21 Smith JG, Nemerow GR: Mechanism of adenovirus neutralization by human alpha-defensins. Cell Host Microbe 2008;3:11-19.

22 Meldrum DR: Tumor necrosis factor in the heart. Am J Physiol 1998;274:R577-R595.

23 Niyonsaba F, Iwabuchi K, Matsuda H, Ogawa $\mathrm{H}$, Nagaoka I: Epithelial cell-derived human $\beta$-defensin- 2 acts as a chemotaxin for mast cells through a pertussis toxin-sensitive and phospholipase C-dependent pathway. Int Immunol 2002;14:421-426.

24 Pazgier M, Hoover DM, Yang D, Lu W, Lubkowski J: Human $\beta$-defensins. Cell Mol Life Sci 2006;63:1294-1313. 